\title{
Maternal tobacco exposure and health-related quality of life during pregnancy: a national-based study of pregnant women in China
}

\author{
Weiwei Sun ${ }^{1,2 \dagger}$, Xinyu Huang ${ }^{1,2 \dagger}$, Huailiang Wu ${ }^{1,2+}$, Casper J. P. Zhang ${ }^{3}$, Zongzhi Yin ${ }^{4}$, Qianqian Fan ${ }^{5}$, \\ Huiyun Wang ${ }^{6}$, Pallavi Jayavanth ${ }^{1,2}$, Babatunde Akinwunmi ${ }^{7,8,9}$, Yanxin Wu ${ }^{10}, Z^{2}$ ilian Wang ${ }^{10}$ and \\ Wai-kit Ming ${ }^{1,2,10^{*}}$ (D)
}

\begin{abstract}
Background: With the increase of the number of smokers, tobacco exposure among pregnant women is becoming more and more common. Pregnant women exposed to first-hand smoke and second-hand smoke are susceptible to physiological and psychological health issues has been proved in previous studies. Nevertheless, there are no enough studies focus on the impact of third-hand smoke during pregnancy. This study aimed to assess and compare healthrelated quality of life for pregnant women with exposure to first-hand smoke, second-hand smoke, third-hand smoke and non-exposure to tobacco in mainland China.
\end{abstract}

Methods: National-based cross-sectional study is based on a questionnaire survey which collects information including demographics, smoking behaviors and self-evaluation. All questionnaires were delivered and collected from August to September 2019. EuroQol group's visual analog scale and EuroQoL Five-dimension Questionnaire were used to collect data in mainland China.

Results: Totally, 15,682 pregnant women were included in this study, among which non-exposure to smoke were 7564 (48.2\%), exposed to first-hand smoke, second-hand smoke and third-hand smoke were 89 (0.6\%), 2349 (15.0\%), and 5680 (36.2\%) respectively. Pregnant women without tobacco exposure had the highest EuroQol group's visual analog scale score (mean value $=85.4[S D=14.0]$ ), while those with first-hand smoke had the lowest score (mean value $=77.4[S D=22.2]$ ). Among all five dimensions of EuroQoL Five-dimension Questionnaire, there were significant differences of EQ-index among groups with different tobacco exposure in usual activity and anxiety or depression dimensions $(p<0.001)$.

Conclusions: Third-hand smoke exposure had close relationship with low health-related quality of life in pregnant women. Moreover, second-hand smoke exposure significantly led more problems on mental dimension of pregnant women.

\footnotetext{
*Correspondence: wkming@connect.hku.hk

†Weiwei Sun, Xinyu Huang and Huailiang Wu have contributted equally to this work

${ }^{1}$ Department of Public Health and Preventive Medicine, School of Medicine, Jinan University, Guangzhou, China

Full list of author information is available at the end of the article
}

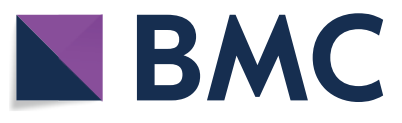

(c) The Author(s) 2021. Open Access This article is licensed under a Creative Commons Attribution 4.0 International License, which permits use, sharing, adaptation, distribution and reproduction in any medium or format, as long as you give appropriate credit to the original author(s) and the source, provide a link to the Creative Commons licence, and indicate if changes were made. The images or other third party material in this article are included in the article's Creative Commons licence, unless indicated otherwise in a credit line to the material. If material is not included in the article's Creative Commons licence and your intended use is not permitted by statutory regulation or exceeds the permitted use, you will need to obtain permission directly from the copyright holder. To view a copy of this licence, visit http://creativecommons.org/licenses/by/4.0/. The Creative Commons Public Domain Dedication waiver (http://creativeco mmons.org/publicdomain/zero/1.0/) applies to the data made available in this article, unless otherwise stated in a credit line to the data. 
Keywords: First-hand smoke, Second-hand smoke, Third-hand smoke, Pregnancy, Health-related quality of life

\section{Background}

Tobacco smoking is a well-known risk factor that can cause series of significant morbidity and mortality worldwide, which accounting for more than 8 million deaths annually in global sphere [1]. However, the number of smokers continued to increase and reached 1.1 billion in the world by 2019 [2, 3]. Asthma, cardiovascular diseases and cancer are the common complications caused by active first-hand smoke (FHS) [4-7]. Except for FHS, second-hand smoke (SHS) and third-hand smoke (THS) are two common ways of passive tobacco exposure [8, 9]. SHS contributes to variable diseases as grave as FHS, and caused an additional deaths of 1.2 million people annually [1]. Although SHS could be avoided by multiple ways for non-smokers, THS is much difficult be avoided because THS indicates residual tobacco smoke and particles deposited on surfaces of subjects and dust which may remain for more than one and half years after smoking [10].

The escalating numbers of smokers cause grave complications in both pregnant women and infants by passive tobacco exposure [11-13]. Studies have stated that although many pregnant women never smoke, they still have great chances to expose to SHS and THS [14], especially smoking from their spouses. A study in Sichuan province, China, has shown that $75.1 \%$ of non-smoking pregnant women are victimized due to chronic smoking habits of respective spouses [15]. Previous studies have shown that tobacco exposure can be considered as one of the major risk factors of adverse maternal outcomes such as ectopic pregnancy and spontaneous abortion [16, 17]. Moreover, depression symptoms among pregnant women is also an established glaring fact due to SHS, and under this situation, the probability of stillbirth and fetal congenital malformation increased to $23 \%$ and $13 \%$ respectively [18]. Prenatal SHS exposure in pregnant women shows variety of adverse effects to infants, such as decline the cognitive functions in infants at 6 months [19]. Therefore, it is necessary to evaluate the negative impacts of tobacco exposure and health conditions of pregnant women from multiple dimensions.

World Health Organization (WHO) defines quality of life as an individual's perception of their position in life in the context of the culture and value systems in which they live and in relation to their goals, expectations, standards and concerns [20]. Health-related quality of life (HRQoL) is an indicator shows how well people are able to function and how they feel about physical, mental, and social dimensions of their lives [21]. The idea of concentration on HRQoL is not only beneficial to people, but also has significant meanings to economic and social assessment, and also important to public policy, community programs and legislation [22-24]. Since modern medicine is not only about curing diseases but also more about prevention [23, 25], assessing the HRQoL of pregnant women exposed to tobacco during pregnancy is as important as that of the pregnancy outcomes.

Considering the importance above, this study aimed to investigate the HRQoL of pregnant women exposed to FHS, SHS and THS and compare impacts of different tobacco exposure during pregnancy since previous studies on THS is not enough. In addition, this study also compared HRQoL in pregnant women under different tobacco exposure in different regions, and investigate the five dimensions of HRQoL in pregnant women.

\section{Materials and methods \\ Study design and population}

This national-based cross-sectional study was designed to investigate the effects of FHS, SHS and THS on HRQoL in pregnant women from mainland China. Questionnaires used in this study was designed based on the Global Tobacco Surveil-lance System [26], and the EuroQoL Groups' five-dimension five-level questionnaire (EQ-5D-5L). EQ-5D-5L consists of the EuroQoL Fivedimension Questionnaire (EQ-5D) and EuroQol group's visual analog scale (EQ-VAS), which is an instrumental questionnaire developed in Europe was used to evaluate the general HRQoL of the people [27, 28]. Previous study has proved that EQ-5D-5L can effectively measure health-related quality of life in pregnant women in the population [29]. The Chinese version of the EQ5D-5L has been proved to be valid and effective that is commonly used to measure HRQoL [30-32]. Patientevaluated HRQoL is a comparably objective index to assess a patient's health status [33]. Each dimension was measured and compared the HRQoL values of pregnant women among different regions in mainland China.

All participants finished the web-based questionnaire delivered by a national platform (Banmi Online maternity school) from August to September, 2019. Pregnant women from 31 provincial administrative units of mainland China were recruited via the national maternity school platform (Banmi Online maternity school). This online platform provides prenatal educational courses to pregnant women based on the mobile app. Pregnant women who used this national platform were asked to participane this study during August to September, 
2019. In total, we collected 16,811 questionnaires from pregnant women aged from 16 to 50 years old. Inclusion criteria of this study were as follows: (1) ethnically Chinese women with live pregnancy; (2) used Banmi Online maternity school from August to September 2019. The exclusion criteria were as follows: (1) pregnant women who did not live in mainland China; (2) missing demographic data. As some overseas Chinese pregnant women also used the online platform, those who do not live in mainland China were excluded from this study $(\mathrm{n}=1114)$. There were 15 participants to be excluded because of missing data.

According to the standards of Chinese CDC, the study was conducted in seven regions of mainland China: (1) Northeast: Heilongjiang, Jilin, Liaoning; (2) North: Beijing, Tianjin, Hebei, Shanxi, Inner Mongolia; (3) Central: Hubei, Hunan, Henan; (4) East: Shanghai, Shandong, Jiangsu, Anhui, Jiangxi, Zhejiang, Fujian; (5) South: Guangdong, Guangxi, Hainan; (6) Northwest: Shaanxi, Gansu, Ningxia, Xinjiang; (7) Southwest: Chongqing, Sichuan, Guizhou, Yunnan, Tibet.

\section{Variables and measurement}

Demographic data included age, gestational age and addresses (provinces and cities). The primary variables in the study include the smoking states of pregnant women (smokers or non-smokers), and husbands (smoked in proximity, smoked but not in the proximity and not smoked). Key assessments included the EQ-5D index and EQ-VAS values. Husband smoking in proximity indicated SHS exposure because pregnant women were directly exposed to tobacco. Husband smoked but not in the proximity indicated THS exposure. Based on previous studies [10,34], although pregnant woman were not exposed to SHS directly, they were also exposed to residual tobacco smoke and particles deposited on clothes and other subjects. For those pregnant women who were non-smokers and their husbands did not smoke were categorized as non-tobacco exposure.

The EQ-5D-5L system is a measurement that includes five dimensions: (1) mobility; (2) self-care; (3) usual activities; (4) pain or discomfort; (5) anxiety or depression.
Each question corresponds to five levels: none; slight; moderate; severe; and extreme severe or unable. Each level in each question is represented by an integer value from 1 to $5[35,36]$. Through the EQ-5D indicator value calculator, the values of different levels for each question are arranged and can be calculated as a single EQ-5D indicator value (such as 12,121) to generate the final HRQoL value. In this manner, 1 indicating the best health state while 0 represents death $[28,29,31]$. Range of EQindex value is in the interval of -0.224 to 0 , and these negative values represent their overall health states (both physical and mental state) are worse than death [31].

EQ-VAS is a self-assessment of respondents' health status. It is presented as a vertical line, dividing from 100 (the imaginable best state of health) to 0 (the imaginable worst state of health). Respondents were asked to draw a line on this scale based on their views on their health status, filling the score in the blank space next to it [37].

\section{Statistical methods}

Data analysis was performed by using Statistical Product and Service Solutions (SPSS) 16.0 for Mac and 25.0 for Win. Normally distributed continuous variables were analyzed by independent sample analysis, and were described using the means standard deviations (SDs). The categorical variables were described using counts and percentages. The dependent variables were the EQindex and EQ-VAS in a skewed distribution; therefore, we used a non-parametric approach to analyze the data.

For the different dimensions in EQ-5D-5L questionnaires, One-Way Analysis of Variance (ANOVA) and non-parametric tests were used to calculated the data. Multiple comparison analysis was also used to compare the difference between groups of exposure. All tests were two-sided, and $p$ value of 0.05 was considered as statistically significant.

\section{Results}

As shown in Table 1, the samples (15,682 in total) were in the average age of 28.6 (4.7) and in average gestational age of 21.0 (9.2), including 7564 pregnant women without tobacco exposure, 2349 pregnant women with SHS

Table 1 The demographic and health-related quality of life of pregnant women with different types of exposure to tobacco

\begin{tabular}{|c|c|c|c|c|c|}
\hline $\begin{array}{l}\text { Total participants } \\
(N=15,682)\end{array}$ & $\begin{array}{l}\text { Non-exposure } \\
(N=7564)\end{array}$ & $\begin{array}{l}\text { FHS } \\
(N=89)\end{array}$ & $\begin{array}{l}\text { SHS } \\
(N=2349)\end{array}$ & $\begin{array}{l}\text { THS } \\
(N=5680)\end{array}$ & $p$ value \\
\hline Age (SD) & $28.6(4.7)$ & $26.2(5.1)$ & $27.5(5.2)$ & $28.6(4.7)$ & $<0.001^{*}$ \\
\hline Gestational age (SD) & $21.0(9.2)$ & $21.8(9.0)$ & $21.5(9.2)$ & $21.1(9.0)$ & 0.82 \\
\hline EQ-index (SD) & $0.804(0.13)$ & $0.808(0.14)$ & $0.796(0.13)$ & $0.807(0.13)$ & 0.07 \\
\hline EQ-VAS (SD) & $85.4(14.0)$ & $77.4(22.2)$ & $80.6(17.6)$ & $84.5(14.9)$ & $<0.001^{*}$ \\
\hline
\end{tabular}

${ }^{*} p$ value $<0.05$ indicates the statistical difference 
exposure, and 5680 pregnant women exposed to THS. EQ-index and EQ-VAS of pregnant women in different groups were reported in Table 1 . There was significant difference of EQ-VAS scores among pregnant women with different tobacco exposure ( $p$ value $<0.001$ ).

The EQ-VAS was in a skewed distribution, and not in equal variance $(\alpha<0.001)$. Therefore, we used Tahmane's T2 method to compare EQ-VAS of pregnant women between different tobacco exposure groups in Table 2 . There were obvious differences in EQ-VAS between non-tobacco exposure and tobacco exposure groups in respect of FHS, SHS, and THS $(p=0.007,<0.001,0.001$ respectively). To be specific, the average score of EQ-VAS for pregnant women with THS exposure was significantly higher than those with FHS and SHS exposed pregnant women ( $p=0.024$ and $<0.001$ respectively). But there was no significant difference in EQ-VAS between FHS pregnant women and SHS pregnant women $(p=0.729)$.

In Table 3, we displayed the different numbers in different levels of EQ-5D dimensions for pregnant women under different types of tobacco exposure, to evaluate the impact on SHS and THS on the different aspects. Among all five dimensions, no matter which types of tobacco exposure, more than half of pregnant women had health problems (value 2-5) on pain or discomfort and anxiety or depression dimensions. There were significant differences of EQ-index scores in usual activity and anxiety or depression dimensions between pregnant women in different groups (both $p<0.001$ ).

For Fig. 1, we depicted the EQ-VAS for pregnant women under different tobacco exposure condition in different regions of mainland China. Pregnant women without tobacco exposure had the highest EQ-VAS value, while pregnant women exposed to SHS had the lowest EQ-VAS value. Pregnant women lived in the northwest region showed obvious lower EQ-VAS lower with the exposure of SHS and THS which indicated a lower level of HRQoL. Besides, pregnant women lived in north region with SHS and THS exposure showed relative higher EQ-VAS score than other regions.

\section{Discussion}

This study explored and compared the HRQoL of pregnant women exposed to FHS, SHS and THS in mainland China. Overall, it showed that tobacco exposure during pregnancy can lead to lower level of HRQoL regardless of the types of exposure (FHS, SHS and THS). Furthermore, our results emphasized that FHS and SHS could cause more severe effects on HRQoL of pregnant women than THS. Also, tobacco exposure during pregnancy has been proved to be a risk factor for HRQoL of pregnant women in this study. This finding is consistent with previous studies in other countries [38-41]. The important health issues and the adverse effects caused by direct maternal tobacco smoking and passive SHS exposure will significantly harm not only pregnant women but also their fetuses or newborns [42-46]. However, there was no previous study examined and compared the impacts of pregnant women exposed to FHS, SHS and THS. This study is the pioneer project to provide empirical evidence on the adverse effect of THS in addition to FHS and SHS. We found that THS had close relationship with lower HRQoL of pregnant women. Although others didn't smoke in front of pregnant women, THS exposure still remained due to residues. Even if people with lower HRQoL might be asymptomatic in the clinic, previous

Table 2 Multiple comparisons of EQ-VAS (Tamhane's T2 method) for pregnant women in different types of tobacco exposure

\begin{tabular}{|c|c|c|c|c|c|c|c|c|}
\hline \multirow{2}{*}{$\begin{array}{l}\text { Types of } \\
\text { tobacco } \\
\text { exposure }\end{array}$} & \multirow[t]{2}{*}{ EQ-VAS } & \multirow[t]{2}{*}{ Comparison group } & \multirow{2}{*}{$\begin{array}{l}\text { Mean } \\
\text { EQ-VAS } \\
\text { score (SD) }\end{array}$} & \multirow[t]{2}{*}{ Mean difference } & \multirow[t]{2}{*}{ Standard error } & \multirow[t]{2}{*}{$p$ value } & \multicolumn{2}{|c|}{ 95\% confidence interval } \\
\hline & & & & & & & Upper bound & Lower bound \\
\hline \multirow[t]{3}{*}{ Non-exposure } & $85.4(14.0)$ & FHS & $77.4(22.2)$ & 0.81 & 2.39 & $0.007^{*}$ & 14.44 & 1.59 \\
\hline & & SHS & $80.6(17.6)$ & 4.88 & 0.40 & $<0.001^{*}$ & 5.92 & 3.83 \\
\hline & & THS & $84.5(14.9)$ & 0.95 & 0.26 & $0.001^{*}$ & 1.62 & 0.28 \\
\hline \multirow[t]{3}{*}{ FHS } & $77.4(22.2)$ & Non-exposure & $85.4(14.0)$ & -0.81 & 2.39 & $0.007^{*}$ & -1.59 & -14.44 \\
\hline & & SHS & $80.6(17.6)$ & -3.14 & 2.41 & 0.729 & 3.34 & -9.61 \\
\hline & & THS & $84.5(14.9)$ & -7.06 & 2.39 & $0.024^{*}$ & -0.63 & -13.49 \\
\hline \multirow[t]{3}{*}{ SHS } & $80.6(17.6)$ & Non-exposure & $85.4(14.0)$ & -4.88 & 0.40 & $<0.001^{*}$ & -3.83 & -5.92 \\
\hline & & FHS & $77.4(22.2)$ & 3.14 & 2.41 & 0.729 & 9.61 & -3.34 \\
\hline & & THS & $84.5(14.9)$ & -3.92 & 0.41 & $<0.001^{*}$ & -2.84 & -5.01 \\
\hline \multirow[t]{3}{*}{ THS } & $84.5(14.9)$ & Non-exposure & $85.4(14.0)$ & -0.95 & 0.26 & $0.001^{*}$ & -0.28 & -1.62 \\
\hline & & FHS & $77.4(22.2)$ & 7.06 & 2.39 & $0.024^{*}$ & 13.49 & 0.63 \\
\hline & & SHS & $80.6(17.6)$ & 3.92 & 0.41 & $<0.001^{*}$ & 5.01 & 2.84 \\
\hline
\end{tabular}

${ }^{*} P$ value $<0.05$ indicates the statistical difference 
Table 3 Levels of EQ-5D dimensions for pregnant women exposed to different types of tobacco

\begin{tabular}{|c|c|c|c|c|c|}
\hline EQ-5D dimension & $\begin{array}{l}\text { Non-exposure } \\
N=7564\end{array}$ & $\begin{array}{l}\text { FHS exposure } \\
N=89\end{array}$ & $\begin{array}{l}\text { SHS exposure } \\
N=2349\end{array}$ & $\begin{array}{l}\text { THS exposure } \\
N=5680\end{array}$ & $p$ value \\
\hline Mobility & & & & & 0.693 \\
\hline 1 & $5832(77.1 \%)$ & 70 (77.8\%) & 1833 (78.0\%) & 4426 (77.9\%) & \\
\hline 2 & $1460(19.3 \%)$ & $17(18.9 \%)$ & 423 (18.0\%) & $1057(18.6 \%)$ & \\
\hline 3 & $217(2.9 \%)$ & $2(2.2 \%)$ & 77 (3.3\%) & $158(2.8 \%)$ & \\
\hline 4 & $27(0.4 \%)$ & $0(0.0 \%)$ & $9(0.4 \%)$ & 20 (0.4\%) & \\
\hline 5 & $28(0.4 \%)$ & $0(0.0 \%)$ & $7(0.3 \%)$ & 19 (0.3\%) & \\
\hline Self-care & & & & & 0.067 \\
\hline 1 & 7077 (93.6\%) & 81 (90.0\%) & 2223 (94.6\%) & $5376(94.6 \%)$ & \\
\hline 2 & $446(5.9 \%)$ & $4(4.4 \%)$ & $111(4.7 \%)$ & 277 (4.9\%) & \\
\hline 3 & $28(0.4 \%)$ & $2(2.2 \%)$ & $11(0.5 \%)$ & $20(0.4 \%)$ & \\
\hline 4 & $4(0.1 \%)$ & $1(1.1 \%)$ & $3(0.1 \%)$ & 4 (0.1\%) & \\
\hline 5 & $9(0.1 \%)$ & $1(1.1 \%)$ & $1(0.0 \%)$ & $3(0.1 \%)$ & \\
\hline Usual activity & & & & & $<0.001^{*}$ \\
\hline 1 & 5925 (78.3\%) & $74(82.2 \%)$ & 1904 (81.1\%) & $4609(81.1 \%)$ & \\
\hline 2 & $1,472(19.5 \%)$ & $10(11.1 \%)$ & 405 (17.2\%) & 960 (16.9\%) & \\
\hline 3 & $121(1.6 \%)$ & $2(2.2 \%)$ & $33(1.4 \%)$ & $87(1.5 \%)$ & \\
\hline 4 & $17(0.2 \%)$ & $1(1.1 \%)$ & $4(0.2 \%)$ & 7 (0.1\%) & \\
\hline 5 & $29(0.4 \%)$ & $2(2.2 \%)$ & $3(0.1 \%)$ & $17(0.3 \%)$ & \\
\hline Pain or discomfort & & & & & 0.218 \\
\hline 1 & $3299(43.6 \%)$ & $44(48.9 \%)$ & $988(42.1 \%)$ & $2523(44.4 \%)$ & \\
\hline 2 & 3291 (51.8\%) & $39(43.8 \%)$ & 1243 (52.9\%) & $2908(51.2 \%)$ & \\
\hline 3 & 295 (3.9\%) & $5(5.6 \%)$ & 107 (4.6\%) & $218(3.8 \%)$ & \\
\hline 4 & $39(0.5 \%)$ & $1(1.1 \%)$ & $8(0.3 \%)$ & $27(0.5 \%)$ & \\
\hline 5 & $10(0.1 \%)$ & $0(0.0 \%)$ & $3(0.1 \%)$ & 4 (0.1\%) & \\
\hline Anxiety or depression & & & & & $<0.001^{*}$ \\
\hline 1 & 3773 (49.9\%) & $36(40.0 \%)$ & $1000(42.6 \%)$ & $2824(49.7 \%)$ & \\
\hline 2 & $3380(44.7 \%)$ & $40(44.4 \%)$ & 1123 (47.8\%) & $2549(44.9 \%)$ & \\
\hline 3 & $339(4.2 \%)$ & $12(13.3 \%)$ & $158(6.7 \%)$ & $256(4.5 \%)$ & \\
\hline 4 & $50(0.7 \%)$ & $0(0.0 \%)$ & 49 (2.1\%) & $41(0.7 \%)$ & \\
\hline 5 & $22(0.3 \%)$ & $1(1.1 \%)$ & $19(0.8 \%)$ & $10(0.2 \%)$ & \\
\hline
\end{tabular}

${ }^{*} p$ value $<0.05$ indicates the statistical difference

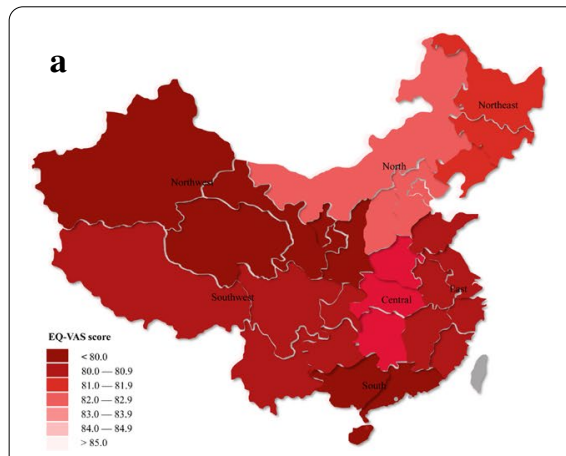

SHS

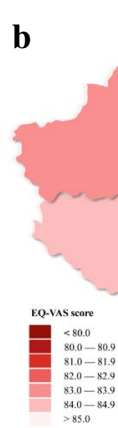

Fig. 1 EQ-VAS for pregnant women under different tobacco exposure condition in different regions of mainland China

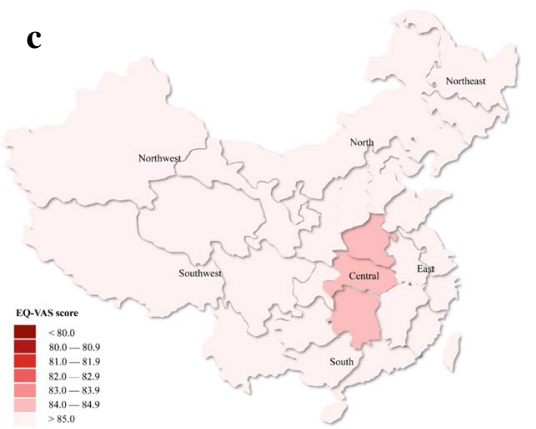

Non-exposure 
study has found that HRQoL has close association with the state of health and clinical outcomes [47].

As mentioned above, it was found that THS had certain adverse impact on HRQoL of pregnant women, but FHS and SHS had more severely negative impacts. This may be explained by the facts that the mechanism of THS was residual tobacco smoke gases and particles settled on surfaces, and they would enter the human body through dermal absorption and ingestion [48, 49]. Through this, the epithelia and mucosa of the respiratory tract could act as protective barriers to prevent the harmful materials and cause a relatively lower level of nicotine dose in human body [50]. Even so, all these three types of tobacco exposure can lead to lower level of HRQoL of pregnant women. Compared to the research findings of other previous studies, we found that pregnant women exposed to FHS and SHS have a similar, and sometimes even much lower HRQoL than those suffered from physiological diseases, such as gestational diabetes mellitus and uterine fibroid $[29,51]$. Although electronic cigarettes has been considered as a safer way than smoking tobacco among people recent years [52], recent studies have stated that e-cigarette products still can cause varying degree of lung damage and chronic respiratory symptoms and both DNA strand breaks and cell death [53-55]; Thus, the usage of e-cigarettes should also be avoided. Overall, it is strongly recommended that pregnant women and their spouses should quit smoking during pregnancy to avoid the massively negative effects of any types of tobacco exposure (FHS, SHS, THS and e-cigarette).

In addition, Fig. 1 revealed that northwest region had relatively lower level of HRQoL under any type of tobacco exposure. This might be related to economic conditions and healthy awareness of pregnant women and their relatives. Previous study has shown that economic conditions are associated with $\mathrm{HRQoL}$ and northwest region had a relatively backward economic condition among total seven regions in mainland China $[22,56]$.

Moreover, this study further analyzed and compared the five dimensions in the EQ-5D-5L scale. It was found that in usual activity and anxiety or depression, different tobacco exposure showed significant differences, especially on anxiety or depression dimension. Pregnant women exposed to SHS had a higher anxiety or depression rate $(57.4 \%)$ than those exposed to THS (50.3\%), which was strongly related to psychological health problems. Preceding findings have shown that exposure to SHS can lead to mentally stressful living environments, while chronic stress or other comorbidities may increase the risk of prevalence of mental disorders [57, 58], indicated a strong correlation between exposure to SHS and negative health effects (such as cancer, respiratory diseases), and all these diseases may lead to depression through direct and indirect multi-step processes. Besides, there was a strong evidence that major depression had close association with SHS exposure [59]. Animal studies showed that SHS adversely affects the dopaminergic system [60]. With long-term exposure to SHS, the levels of dopamine and $\gamma$-aminobutyric acid (GABA) are reduced, which is also associated with an increased risk of depression [61].

In summary, exposure to tobacco has certain negative impacts on the HRQoL of pregnant women even when their spouses did not smoke in the proximity of them. A better HRQoL is more conducive to the health of both pregnant women and fetuses. These findings can help to evaluate the negative impacts of different types of tobacco exposure during pregnancy and provide more clinical evidences on the implementation of pregnant tobacco-control policies. According to these, we call on higher level of healthy education during pregnancy for pregnant women themselves and their spouses and other household relatives, because they may do not have enough understanding of HRQoL and lack awareness about harmful effects of tobacco exposure. Moreover, spouses and household relatives should avoid smoking in front of pregnant women even if smoking is unavoidable. Due to the evidence that THS could also affect the HRQoL of pregnant women, future clinicians and scientists can pay more attention to the study of THS, to ensure overall better pregnancy outcomes.

\section{Strengths and limitations}

The main strength of this study is to focus on HRQoL in pregnant women exposed to different types of exposure to tobacco smoke in China, especially the comparison between SHS and THS. In addition, the large sample size from different regions in mainland China contributes to the good understanding and comparisons of HRQoL of pregnant women in different areas. The major limitation is that the EQ-5D and EQ-VAS are relatively subjective measurements of pregnant women's HRQoL. Thus, the self-reported bias may be the main bias in this study. Less data of pregnant women exposed to FHS was another limitation, this might be explained by that a high level of prenatal education in China, and most pregnant women do not actively smoke. Our aim was to understand the impact of the husband on pregnant women during pregnancy, so as to give pregnant women and their husbands some clinical recommendation. However, potential SHS and THS exposures of pregnant women coming from different sources rather than their husbands are not considered, such as tobacco exposure from the place where pregnant women work or perform other daily activities. And we will conduct follow-up studies to explore the impact of tobacco exposures from different sources on 
pregnant women. Other socio-demographic factors such as economic situation may also affect our results. Figure 1 was based on pregnant women's geographical location, and the results showed HRQoL of pregnant women in the northwest region, which had relatively backward economic conditions $[22,56]$, was slightly lower than in other regions. However, we did not have the individual level of socio-demographic factors which was a limitation to this aspect.

\section{Conclusions}

Pregnant women exposed to tobacco gases and particles had significantly lower HRQoL regardless of types of tobacco exposure (FHS, SHS and THS). FHS and SHS exposure could cause more health problems on pregnant women's mental health than THS exposure. Therefore, our study advocates that pregnant women and their spouses should quit smoking during pregnancy. If tobacco exposure can't be avoided in some special situation, refraining from smoking in front of pregnant women would be a better choice. Besides, the government should strengthen the prenatal education for pregnant women and their spouses to introduce the specific hazards of both active and passive smoking, increasing their awareness to protect the pregnant women from the harms of tobacco.

\section{Abbreviations \\ FHS: First-hand smoke; SHS: Second-hand smoke; THS: Third-hand smoke; HRQOL: Health-related quality of life.}

\section{Acknowledgements}

The authors would like to gratefully acknowledge the participants, collaborators and Banmi Online Maternity School.

\section{Authors' contributions}

WS, $\mathrm{XH}$ and HW contributed equally. WS contributed to the conception and design of work, analysis and interpretation of data, design of tables and figures, drafting and modification of the manuscript, revise of the final version of the manuscript. XH contributed to the conception and design of work, analysis and interpretation of data, design of tables and figures, drafting and modification of the manuscript, revise of the final version of the manuscript. HW contributed to the conception and design of work, analysis and interpretation of data, design of tables and figures, drafting and modification of the manuscript, revise of the final version of the manuscript. CJPZ contributed to analysis and interpretation of data, revise of the final version of the manuscript. ZY contributed to drafting and modification of the manuscript, revise of the final version of the manuscript. QF contributed to interpretation of data, revise of the final version of the manuscript. HW contributed to interpretation of data, revise of the final version of the manuscript. PJ contributed to drafting and modification of the manuscript, revise of the final version of the manuscript. Babatunde Akinwunmi contributed to drafting and modification of the manuscript, revise of the final version of the manuscript. YW contributed to revise of the final version of the manuscript; ZW contributed to drafting and modification of the manuscript, revise of the final version of the manuscript. W-kM contributed to the conception and design of work, revise of the final version of the manuscript. All authors read and approved the final manuscript.
Funding

Not applicable.

\section{Availability of data and materials}

The datasets used and analyzed during the current study are available from the corresponding author on reasonable request.

\section{Declarations}

Ethics approval and consent to participate

Ethical issue was approved by the Institutional Review Board of the First Affiliated Hospital of Sun Yat-sen University (ICE-2017-296). All procedures were conducted in accordance with the Declaration of Helsinki. Participation consent was sought from all subjects.

\section{Consent for publication}

Not applicable.

\section{Competing interests}

The authors declare that they have no competing interests.

\section{Author details}

${ }^{1}$ Department of Public Health and Preventive Medicine, School of Medicine, Jinan University, Guangzhou, China. ${ }^{2}$ International School, Jinan University, Guangzhou, China. ${ }^{3}$ School of Public Health, LKS Faculty of Medicine, The University of Hong Kong, Hong Kong, China. ${ }^{4}$ Department of Obstetrics and Gynecology, The First Affiliated Hospital of Anhui Medical University, Hefei, China. ${ }^{5}$ Department of Pharmacy, Peking Union Medical College Hospital, Beijing, China. ${ }^{6}$ School of Pharmacy, JiNing Medical University, Jining, China. ${ }^{7}$ Maternal-Fetal Medicine Unit, Department of Obstetrics and Gynecology, Brigham and Women's Hospital, Boston, USA. ${ }^{8}$ Center for Genomic Medicine, Massachusetts General Hospital, Boston, USA. ${ }^{9}$ Harvard Medical School, Harvard University, Boston, MA, USA. ${ }^{10}$ Department of Obstetrics and Gynaecology, The First Affiliated Hospital of Sun Yat-Sen University, Guangzhou, China.

Received: 29 April 2020 Accepted: 3 May 2021

Published online: 20 May 2021

\section{References}

1. Tobacco [https://www.who.int/health-topics/tobacco].

2. Navas-Acien A. Global tobacco use: old and new products. Ann Am Thorac Soc. 2018;15:569-575.

3. Tobacco-Key facts [https://www.who.int/news-room/fact-sheets/detail/ tobacco].

4. Hecht SS. Tobacco carcinogens, their biomarkers and tobacco-induced cancer. Nat Rev Cancer. 2003;3:733-44.

5. Yang G. Cancer prevention and tobacco control. Zhonghua Yu Fang Yi Xue Za Zhi. 2015;49:292-4.

6. de Granda-Orive JI, Solano-Reina S, de Granda-Beltran AM, JimenezRuiz C. Asthma and tobacco: dangerous liaisons. Ann Epidemiol. 2017;27:406-7.

7. Ambrose JA, Barua RS. The pathophysiology of cigarette smoking and cardiovascular disease: an update. J Am Coll Cardiol. 2004;43:1731-7.

8. Florescu A, Ferrence R, Einarson T, Selby P, Soldin O, Koren G. Methods for quantification of exposure to cigarette smoking and environmental tobacco smoke: focus on developmental toxicology. Ther Drug Monit. 2009;31:14-30.

9. Environmental Tobacco Smoke (ETS): General information and health effects [https://www.ccohs.ca/oshanswers/psychosocial/ets_health. html].

10. Ramirez N, Ozel MZ, Lewis AC, Marce RM, Borrull F, Hamilton JF. Exposure to nitrosamines in thirdhand tobacco smoke increases cancer risk in nonsmokers. Environ Int. 2014;71:139-47.

11. Hawsawi AM, Bryant LO, Goodfellow LTJRC. Association between exposure to secondhand smoke during pregnancy and low birthweight: a narrative review. Respir Care. 2014;60:135-40.

12. Vardavas Cl, Fthenou E, Patelarou E, Bagkeris E, Murphy S, Hecht SS, Connolly GN, Chatzi L, Kogevinas MJTC. Exposure to different sources 
of secondhand smoke during pregnancy and its effect on urinary cotinine and tobacco-specific nitrosamine (NNAL) concentrations. Tob Control. 2013;22:194-200.

13. Wu P. Maternal smoking during pregnancy and its effect on childhood asthma [J]. Am J Respir Crit Care Med. 2012;186(10):941.

14. Golan R, Kloog I, Almog R, Gesser-Edelsburg A, Negev M, Jolles M, Shalev V, Eisenberg VH, Koren G, Abu Ahmad W, Levine H. Environmental exposures and fetal growth: the Haifa pregnancy cohort study. BMC Public Health. 2018;18:132.

15. Yang L, Tong EK, Mao Z, Hu TW. Exposure to secondhand smoke and associated factors among non-smoking pregnant women with smoking husbands in Sichuan province, China. Acta Obstet Gynecol Scand. 2010;89:549-57.

16. Gould GS, Lim LL, Mattes J. Prevention and treatment of smoking and tobacco use during pregnancy in selected indigenous communities in high-income countries of the United States, Canada, Australia, and New Zealand an evidence-based review. Chest. 2017;152:853-66.

17. Abraham M, Alramadhan S, Iniquez C, Duijts L, Jaddoe VWV, Den Dekker HT, Crozier S, Godfrey KM, Hindmarsh P, Vik T, et al. A systematic review of maternal smoking during pregnancy and fetal measurements with meta-analysis. PLoS ONE. 2017;12:e0170946.

18. Leonardi-Bee J, Britton J, Venn A. Secondhand smoke and adverse fetal outcomes in nonsmoking pregnant women: a meta-analysis. Pediatrics. 2011:127:734-41.

19. Lee BE, Hong YC, Park H, Ha M, Kim JH, Chang N, Roh YM, Kim BN, Kim $Y$, Oh SY, et al. Secondhand smoke exposure during pregnancy and infantile neurodevelopment. Environ Res. 2011;111:539-44.

20. Health statistics and information systems [https://www.who.int/healt hinfo/survey/whoqol-qualityoflife/en/].

21. Hays RD, Reeve BB. Measurement and modeling of health-related quality of life. In International encyclopedia of public health. 2008:241-252.

22. Diener E, Suh E. Measuring quality of life: economic, social and subjective indicators. Soc Indic Res. 1997:40:189-216.

23. Zhihao T. Improving quality of life. China Daily. 2014.

24. Hsieh C-M. Importance is not unimportant: the role of importance weighting in QOL measures. Soc Indic Res. 2012;109:267-78.

25. Sen MNA. The quality of life. Clarendon Press; 1993.

26. Group GC. The global tobacco surveillance system. Tob Control. 2006;15(Suppl 2):ii1-3.

27. Gianluigi Balestroni GB. EuroQol-5D (EQ-5D): an instrument for measuring quality of life. 2012.

28. Ramos-Goñi JM, Oppe M, Slaap B, Busschbach JJV, Stolk EJVIH. Quality control process for EQ-5D-5L valuation studies. Value in Health. 2017;20:466-73.

29. Ming WK, Wu H, Wu Y, Chen H, Meng T, Shen Y, Wang Z, Huang X, Sun $W$, Chow TS, et al. Health-related quality of life in pregnancy with uterine fibroid: a cross-sectional study in China. Health Qual Life Outcomes. 2019;17:89.

30. Luo N, Liu G, Li M, Guan H, Jin X, Rand-Hendriksen K. Estimating an EQ5D-5L value set for China. Value Health. 2017;20:662-9.

31. Luo N, Cheung YB, Ng R, Lee CF. Mapping and direct valuation: do they give equivalent EQ-5D-5L index scores? Health Qual Life Outcomes. 2015:13:166.

32. Lee CF, Ng R, Luo N, Wong NS, Yap YS, Lo SK, Chia WK, Yee A, Krishna $L$, Wong $C$, et al. The English and Chinese versions of the five-level EuroQoL Group's five-dimension questionnaire (EQ-5D) were valid and reliable and provided comparable scores in Asian breast cancer patients. Support Care Cancer. 2013;21:201-9.

33. Thomas M, Gill ARF. A critical appraisal of the quality of quality-of-life measurements. JAMA. 1994;272:619-26.

34. Lidón-Moyano C, Fu M, Pérez-Ortuño R, Ballbè M, Garcia E, MartínSánchez JC, Pascual JA, Fernández E, Martínez-Sánchez JM. Third-hand exposure at homes: Assessment using salivary cotinine. Environ Res. 2020:110393

35. Herdman M, Gudex C, Lloyd A, Janssen M, Kind P, Parkin D, Bonsel G, Badia $X$. Development and preliminary testing of the new five-level version of EQ-5D (EQ-5D-5L). Qual Life Res. 2011;20:1727-36.

36. Richard Brooks wtEG: EuroQol: the current state of play. Health policy. 1996.

37. Feng Y, Parkin D, Devlin NJ. Assessing the performance of the EQ-VAS in the NHS PROMs programme. Qual Life Res. 2014;23:977-89.
38. Moga M, Preda GH. Smoking in pregnancy. J Environ Prot Ecol. 2008;9:566-73.

39. Tsakiridis I, Dagklis T, Zerva C, Mamopoulos A, Athanasiadis A, Papazisis G. Depression in pregnant women hospitalized due to intrauterine growth restriction: prevalence and associated factors. Midwifery. 2019;70:71-5.

40. Kim YW, Lee CH, Park YS, Kim Yl, Ahn CM, Kim JO, Park JH, Lee SH, Kim $J Y$, Chun EM, et al. Effect of exposure to second-hand smoke on the quality of life: a nationwide population-based study from South Korea. PLOS ONE. 2015;10:e0138731.

41. Kalayasiri R, Supcharoen W, Ouiyanukoon P. Association between secondhand smoke exposure and quality of life in pregnant women and postpartum women and the consequences on the newborns. Qual Life Res. 2018;27:905-12.

42. Chomba E, Tshefu A, Onyamboko M, Kaseba-Sata C, Moore J, McClure EM, Moss N, Goco N, Bloch M, Goldenberg RL. Tobacco use and secondhand smoke exposure during pregnancy in two African countries: Zambia and the Democratic Republic of the Congo. Acta Obstetr Gynecol Scand. 2010;89:531-9.

43. Bloch M, Althabe F, Onyamboko M, Kaseba-Sata C, Castilla EE, Freire S, Garces AL, Parida S, Goudar SS, Kadir MM. Tobacco use and secondhand smoke exposure during pregnancy: an investigative survey of women in 9 developing nations. Am J Public Health. 2008;98:1833-40.

44. Hernández-Martínez C, Val VA, Subías JE, Sans JC. A longitudinal study on the effects of maternal smoking and secondhand smoke exposure during pregnancy on neonatal neurobehavior. Early Hum Dev. 2012;88:403-8.

45. Roquer JM, Figueras J, Botet F, Jimenez R. Influence on fetal growth of exposure to tobacco smoke during pregnancy. Acta Paediatr. 1995;84:118-21.

46. Hawkins SS, Berkman L. Identifying infants at high-risk for second-hand smoke exposure. Child Care Health Dev. 2014;40:441-5.

47. Pinkas J, Gujski M, Humeniuk E, Raczkiewicz D, Bejga P, Owoc A, Bojar I. State of health and quality of life of women at advanced age. Med Sci Monit. 2016:22:3095-105.

48. Kuo HW, Rees VW. Third-hand smoke (THS): what is it and what should we do about it? J Formos Med Assoc. 2019;118:1478-9.

49. Acuff L, Fristoe K, Hamblen J, Smith M, Chen J. Third-hand smoke: old smoke new concerns. J Community Health. 2016;41:680-7.

50. Yuksel H, Turkeli A. Airway epithelial barrier dysfunction in the pathogenesis and prognosis of respiratory tract diseases in childhood and adulthood. Tissue Barriers. 2017;5:e1367458.

51. Pantzartzis KA, Manolopoulos PP, Paschou SA, Kazakos K, Kotsa K, Goulis DG. Gestational diabetes mellitus and quality of life during the third trimester of pregnancy. Qual Life Res. 2019;28:1349-54.

52. Harrell PT, Simmons VN, Correa JB, Padhya TA, Brandon TH. Electronic nicotine delivery systems ("E-cigarettes"): review of safety and smoking cessation efficacy. Otolaryngol Head Neck Surg. 2014;151:381-93.

53. Ferkol TW, Farber HJ, Stefania LG, Leone FT, Marshall HM, Enid N, et al. Electronic cigarette use in youths: a position statement of the forum of international respiratory societies. Eur Respir J. 2018;51(5):1800278.

54. Yu V, Rahimy M, Korrapati A. Electronic cigarettes induce DNA strand breaks and cell death independently of nicotine in cell lines. Oral Oncol. 2016;52:58-65.

55. Holliday R, Kist R, Bauld L. E-cigarette vapour is not inert and exposure can lead to cell damage. Evid-based Dent. 2016;17:2.

56. Wen Y. Research on the regional gaps and its changes of the provincial urbanization levels in China. Areal Research and Development. 2005.

57. Asbridge M, Ralph K, Stewart S. Private space second-hand smoke exposure and the mental health of non-smokers: a cross-sectional analysis of Canadian adults. Addict Behav. 2013;38:1679-86.

58. Nakai Y, Inoue T, Toda H, Toyomaki A, Nakato Y, Nakagawa S, Kitaichi Y, Kameyama R, Hayashishita Y, Wakatsuki Y, et al. The influence of childhood abuse, adult stressful life events and temperaments on depressive symptoms in the nonclinical general adult population. J Affect Disord. 2014;158:101-7.

59. Patten SB, Williams JVA, Lavorato DH, Woolf B, Wang JL, Bulloch AGM, Sajobi T. Major depression and secondhand smoke exposure. J Affect Disord. 2018;225:260-4. 
60. Danielson K, Putt F, Truman P, Kivell BM. The effects of nicotine and tobacco particulate matter on dopamine uptake in the rat brain. Synapse. 2014;68:45-60.

61. Petty F. GABA and mood disorder: a brief review hypothesis. 1995

\section{Publisher's Note}

Springer Nature remains neutral with regard to jurisdictional claims in published maps and institutional affiliations.
Ready to submit your research? Choose BMC and benefit from:

- fast, convenient online submission

- thorough peer review by experienced researchers in your field

- rapid publication on acceptance

- support for research data, including large and complex data types

- gold Open Access which fosters wider collaboration and increased citations

- maximum visibility for your research: over 100M website views per year

At BMC, research is always in progress.

Learn more biomedcentral.com/submissions 